\title{
Detection of Fungi in Hair-brushes in Beauty Salons at Jatinangor
}

\author{
Susanna Mitchelle Edward, ${ }^{1}$ Imam Megantara, ${ }^{2}$ Reiva Farah Dwiyana ${ }^{3}$ \\ ${ }^{1}$ Faculty of Medicine Universitas Padjadjaran, ${ }^{2}$ Department of Microbiology and Parasitology \\ Faculty of Medicine Universitas Padjadjaran, ${ }^{3}$ Department of Dermato-venereology Faculty of \\ Medicine Universitas Padjadjaran/Dr. Hasan Sadikin General Hospital Bandung
}

\begin{abstract}
Background: Various beauty tools are used in beauty salons, among those is the hair-brush. The hair-brush can conceal various human skin pathogens although under harsh environmental conditions, most pathogens are killed; nevertheless, few microorganisms, such as the fungi can adapt and survive. Moreover, the moist conditions of the hair-brush predisposes the growth of fungi, however the ability of these fungi to instigate disease in an individual is dependent on the portal of entry and the host immunological status. This study was conducted to determine the fungus that is present in the beauty salon's hair-brushes.

Methods: This study was conducted in beauty salons located in Jatinangor area during September-October 2013 using the descriptive laboratory method. Fifteen beauty salons were included in this study based on sample size calculation for dichotomous variable. The specimens from all the hair-brushes were collected after the owner's informed consent, then cultured onto 30 sabouraud agar, two for each beauty salon (dermatophyte and non-dermatophyte agar). The fungi were detected macroscopically and microscopically. Results: Overall, $93 \%$ revealed to be culture positive, with $90 \%$ of them were found to be non-dermatophytes, most of which are saprophytic fungi. The remaining $3 \%$ were dermatophytes.

Conclusions: Beauty salon's hair-brushes contain a wide range of fungi distribution which may be a source of fungal colonization. However, most of the fungi found in the beauty salons are saprophytic fungi, therefore it is unnecessary to be anxious about a small amount of pathogenic fungi are found in humans. [AMJ.2015;2(4):516-20]
\end{abstract}

Keywords: Beauty salon, dermatophyte, non-dermatophyte, hair-brush

\section{Introduction}

Hairdressing is aided by various tools, however, the hairbrush is the most commonly used tool in beauty salons. Hair-brushes may conceal various human skin pathogens such as bacteria, fungi, ticks and nits due to contact with many customers with different types of hair and scalp conditions. ${ }^{1}$ Consequently, when these pathogens come in contact with another human scalp the chances of infection and infestations is increased. ${ }^{2}$ On the other hand, disease manifestation varies, and is dependent on the portal of entry of microorganisms and the individual's immune status. ${ }^{3}$

According to a study conducted in Pakistan ${ }^{4}$ it notes that the third most common species found in the beauty salon's beauty tools is the fungus. Similar to bacteria, some of the fungus is also a part of the normal human flora. It becomes potentially pathogenic under various conditions, resulting into mycoses. On the other hand, fungus from the environment can also produce infection when it comes in contact with an exposed individual.

The beauty salon hair-brushes being moist upon contact of usage create a favorable environment for the fungi growth. These fungi could originate either from the closed indoor environment or from the scalp and hair of an infected customer, predisposing the risk of transmission as the beauty salons often use the same hair-brushes to all the customers.

In Indonesia, current knowledge is lacking in this field thus limiting the perspectives of this potentially harmful human pathogens. Jatinangor has become a crowded area since several universities are located there, and the number of visits of customers to salons is increasing. This study was conducted to determine the fungus that is present in the beauty salon's hair-brushes at Jatinangor.

Correspondence: Susanna Mitchelle Edward, Faculty of Medicine, Universitas Padjadjaran, Jalan Raya BandungSumedang Km.21, Jatinangor, Sumedang, Indonesia, Phone: +6285624202258 Email: susannamitchelle@gmail.com 


\section{Methods}

This study was carried out from SeptemberOctober 2013, the samples were collected and then cultured in the Microbiology Laboratory of Faculty of Medicine, Universitas Padjadjaran, Jatinangor, using the laboratory descriptive method. This study was approved by the Health Research Ethics Committee Faculty of Medicine Universitas Padjadjaran. With consent of the participating beauty salons, samples were collected from all the hairbrushes used by scrapping the hair-brushes in the beauty salons.

The scales were then collected in a black envelope, one envelope for each beauty salon. The inclusion criterion was all the hairbrushes that have been used on customers. Above and beyond, samples were only collected from beauty salons operating during the period of research and located along in Jatinangor area. Along with the informed consent form, beauty salon operators were interviewed on frequency and methods of cleaning hairbrushes.

From the 15 participating beauty salons, samples were obtained by scrapping the hairbrushes along its bristles. Scales that had been collected in black envelopes were then examined in the laboratory were then transported to the laboratory directly. Each sample from the beauty salons was cultured in two different culture media: an agar contained Sabouraud agar with chloramphenicol, and
Table 1 Type of Fungi that Grows on Culture

\begin{tabular}{lc}
\hline Fungi & $\begin{array}{c}\text { Number of Culture } \\
\text { Positive }\end{array}$ \\
\hline Dermatophyte & 1 \\
Non-dermatophyte & 27 \\
None & 2 \\
\hline
\end{tabular}

the other agar contained Sabouraud agar with chloramphenicol and cycloheximide.

Cultures were left at room temperature and observed daily macroscopically and microscopically for four weeks. Based on morphology appearance of colony, fungi were detected macroscopically and then detection was pursued microscopically. Then, microscopically, cultures were observed using 10-40X magnification with $10 \%$ potassium hydroxide solution and/or lactophenol cotton blue. The presence of hyphae and/ or spores was used to indicate positive fungi growth. The fungi was then grouped as dermatophytes and non-dermatophytes based on its characteristics. Then, all mycological data obtained were tabulated and counted for its frequency and percentage using statistical program.

\section{Results}

Non-dermatophyte is higher in number than non-dermatophytes (Table 1). The three most

Table 2 Frequency of Occurrence based on Fungi Colonies

\begin{tabular}{lcc}
\hline Fungus Colony & Number of Colony & Percentage (\%) \\
\hline Aspergillus & 13 & 24.07 \\
Fonsecaea & 8 & 14.81 \\
Penicillium & 7 & 12.96 \\
Candida & 6 & 11.11 \\
Cephalosporium & 5 & 9.26 \\
Mucor & 5 & 9.26 \\
Rhodotorula & 3 & 5.56 \\
Mycelia sterila & 2 & 3.70 \\
Gliocaldium & 1 & 1.85 \\
Malassezia & 1 & 1.85 \\
Phialophora & 1 & 1.85 \\
Rhizopus & 1 & 1.85 \\
Trichophyton & 1 & 1.85 \\
Total & 54 & 100 \\
\hline
\end{tabular}

Note:* meaning colony of same genus in the same culture is counted as one 
Table 3 Methods and Frequency of Cleaning Hairbrushes with Detected Colonies

\begin{tabular}{|c|c|c|c|}
\hline $\begin{array}{l}\text { Beauty } \\
\text { Salon }\end{array}$ & Type of Colony & Methods* & $\begin{array}{c}\text { Frequency of Cleaning } \\
\text { per Week }\end{array}$ \\
\hline A & Aspergillus & I & 1 \\
\hline B & $\begin{array}{l}\text { Aspergillus,Candida, Cephalosporium,Fonsecaea } \\
\text { and Penicillium }\end{array}$ & I & 1 \\
\hline $\mathrm{C}$ & $\begin{array}{l}\text { Aspergillus,Cephalosporium, Fonsecaea and } \\
\text { Penicillium }\end{array}$ & $\mathrm{I}$ & 1 \\
\hline $\mathrm{D}$ & $\begin{array}{l}\text { Aspergillus, Candida,Cephalosporium, } \\
\text { Fonsecaea and Mucor }\end{array}$ & $\mathrm{X}$ & - \\
\hline $\mathrm{E}$ & Aspergillus, Candida and Penicillium & II & 1 \\
\hline $\mathrm{F}$ & $\begin{array}{l}\text { Aspergillus, Candida, Fonsecaea, Mucor, Mycelia } \\
\text { sterilia, Rhodotrula and Rhizopus }\end{array}$ & II & 1 \\
\hline G & $\begin{array}{l}\text { Aspergillus, Mucor, Penicillium, Phialophora } \\
\text { and Rhodotorula }\end{array}$ & II & 1 \\
\hline $\mathrm{H}$ & $\begin{array}{l}\text { Apergillus, Cephalosporium, Fonsecaea and } \\
\text { Rhodotorula }\end{array}$ & $\mathrm{X}$ & - \\
\hline I & Fonsecaea and Penicillium & I & every 2 days \\
\hline $\mathrm{J}$ & Aspergillus & I & everyday \\
\hline $\mathrm{K}$ & Aspergillus, Malassezia and Penicillium & I & 1 \\
\hline $\mathrm{L}$ & $\begin{array}{l}\text { Aspergillus, Candida, Fonsecaea and Mycelia } \\
\text { sterilia }\end{array}$ & II & everyday \\
\hline M & Aspergillus and Trichophyton & $\mathrm{X}$ & - \\
\hline $\mathrm{N}$ & Aspergillus, Gliocaldium, Mucor and Penicillium & I & 1 \\
\hline 0 & Candida, Cephalosporium, Fonsecaea and Mucor & II & 1 \\
\hline
\end{tabular}

*Note: I=Beauty salons which clean using hot water and shampoo, II= beauty salons whichclean using hot water with common washing detergent and $\mathrm{X}=$ beauty salons which clean without washing

common fungi are the Aspergillus, Fonsecae and the Penicillum species. The truly pathogenic fungi, Trichophyton sp. was found as the lowest in number (Table 2).

Furthermore, the types of colony found in each beauty salon as well as the cleaning method used and frequency of cleaning showed that all beauty salons had fungal contamination. Most beauty salons cleaned the hair-brushes using hot water and shampoo, some cleaned with hot water and a common detergent and a few beauty salons did not clean in the context of washing. Furthermore, most of the beauty salons cleaned the hairbrushes once a week (Table 3).

Trichophyton species were found in beauty salons that never washed the hair-brushes and Candida was mostly found in beauty salons that cleaned the hairbrushes by washing with a common detergent. In beauty salons that washed the hairbrushes once a week lesser Candida wasfound (Table 4).

\section{Discussion}

It is observed that most of the fungi present are the saprophytic fungi. They are present everywhere or are in fact as laboratory contaminant. In contrast, the presence of the Malassezia sp., Candida and Trichopyton sp. means that there are chances of an individual acquiring the superficial mycoses when the host defenses are overcome (Table 2).

Furthermore,Malassezia sp ispartofanormal microbial flora in human. Transmissions of Malassezia are potentially high when the same fomites such as the hairbrushes are used on a healthy person. Nonetheless, Malassezia $s p$. can cause disease only when it takes the mycelium form. The change from normal flora, yeast phase to mycelium form is dependent on various factors such as increased sebum production, hyperhidrosis, malnutrition and immunocompromised conditions that assist the colonization of this species. Thus it can lead 


\section{Table 4 Fungi Capable of Causing Cutaneous Mycoses with Frequency and Methods of} Cleaning Hairbrushes

\begin{tabular}{lcc}
\hline \multirow{1}{*}{ Fungi } & Dermatophytes & Non-dermatophytes \\
\cline { 2 - 3 } & Trichophyton, $\mathrm{n}(\%)$ & Candida, $\mathrm{n}(\%)$ \\
\hline Methods of cleaning* & $1(14.29)$ \\
Wash with shampoo & & $4(57.14)$ \\
Wash with common detergent & $1(14.29)$ & $1(14.29)$ \\
Never wash & & \\
Frequency of washing & $1(14.29)$ & $1(14.29)$ \\
Never & & $4(57.14)$ \\
$1 \mathrm{x}$ & & $1(14.29)$ \\
Every 2 days &
\end{tabular}

to conditions such as dandruff and folliculitis. ${ }^{5}$

Relevant to the research the cutaneous mycoses was discussed in depth as the fungi in this group could affect the keratinized hair structure and skin. In this study, Candida and Trichophyton dermatophyte were discussed. In addition, a similar study was conducted in Turkey ${ }^{6}$ whereby barber's tools were examined to detect fungi, and the fungi found found are mostly the non-dermatophytic molds, Trichophyton rubrum and Candida albicans.

Likewise, Candida was also found in six of the beauty salons. Its presence on the skin surfaces is not harmful in a healthy person since it isa normal flora of the skin. Conversely, it may cause opportunistic infections such as folliculitis in immunocompromised persons.

In comparison with previous studies, the dermatophytes that are mostly found as an etiologic agent for tinea capitis is the Trichophyton $\mathrm{sp}^{7,8}$ Likewise, in the current research , the dermatophytes detected was the Trichophyton rather than the Microsporum sp.. In tropical regions such as in Asia, the Trichophyton violacelum is the most common cause of tinea capitis. ${ }^{8}$ Furthermore, the findings of the Trichophyton dermatophyte can be blamed on the fact that Indonesia is located in thetropical region. ${ }^{9}$ Therefore, the humidity, moisture and suitable temperature precipitate the growth of this fungus.

It can be observed that Candida sp. were present most in beauty salons that washed the hairbrushes using hot water and a common washing detergent, compared to beauty salons that never washed hair-brushes and those beauty salon that cleaned hair-brushes by using hot water and shampoo (Table 3). The presence of fungi which appeared higher in number in beauty salons that washed with common washing detergent may be due to the detergent which does not have fungicidal properties hence, upon washing it created a wet, moist condition that favors the fungal growth.10 The poor distribution of fungi in cleaning methods using hot water and shampoo could be due to the fungicidal properties. Beauty salons that never wash the hair-brushes conceal fungi that are invisible to the naked eyes; as a result chances of transmissions are increased. Therefore, methods of cleaning might affect the nondermatophyte fungus growth. In this research, dermatophytes were the only truly pathogenic fungi found in beauty salons which never washed the hair-brushes.

Consequently, there are risks of transmission when the hair-brushes containing these species came in contact with the host. Mostly, colonization of these species does not cause significant morbidity but it can cause psychological embarrassment to individuals. $^{2}$

In conclusion, the beauty salons' hairbrushes contain a wide range of fungi distribution which may be a source of fungal colonization. Most hairbrushes from beauty salons in Jatinangor contain the nondermatophyte fungi. Regardless of some of the non-dermatophytes being a normal flora of the skin, it can become potentially pathogenic under various conditions such as hyperhydrosis, malnourishment and weakened immune status. The finding of the 
truly pathogenic fungi were low, nevertheless, the hygiene of beauty salon hair-brushes must be improved by implementing good practices of disinfection and sanitation such as periodic cleaning using a proper cleaning method can hinder the growth of microorganisms such as fungi.

There are few weaknesses in this study since this study lacks the view of a mycologist. In addition, the sample size used was not large enough. Therefore, in a further study on this topic, a larger sample size is recommended. There should be comprehensive studies related to the causal relationship of predisposing factors and distribution of fungi in beauty salon hair-brushes.

\section{References}

1. Henderson S. Basic hairdressing: a course book for level 2. Cheltenham: Nelson Thornes; 2003. p. 53-55

2. Grimalt R. A practical guide to scalp disorders. J Investig Dermatol Symp Proc. 2007;12(2):10-4.

3. Enemuor S, Atabo A, Oguntibeju 0 . Evaluation of bacterial and fungal contamination in hairdressing and beauty beauty salons. Sci Res Essays. 2013;7(14): 1222-25.

4. Naz S, Iqtedar $\mathrm{M}$, ul Ain $\mathrm{Q}$ Aftab $\mathrm{K}$.
Incidence of Human Skin Pathogens from cosmetic tools used in beauty salons in different areas of Lahore, Pakistan. J Sci Res. 2012;4(2):523-7.

5. Inamadar AC, Palit A. The genus Malassezia and human disease. Indian J Dermatol Venereol Leprol. 2003;69(4):265-70.

6. Uslu H, Uyanik M, Ayyildiz A. Mycological examination of the barbers' tools about sources of fungal infections. Mycoses. 2008;51(5):447-50.

7. Foster KW, Ghannoum MA, Elewski BE. Epidemiologic surveillance of cutaneous fungal infection in the United States from 1999 to 2002. J Am Acad Dermatol. 2004;50(5):748-52.

8. Akbaba M, Ilkit M, Sutoluk Z, Ates A, Zorba $H$. Comparison of hairbrush, toothbrush and cotton swab methods for diagnosing asymptomatic dermatophyte scalp carriage. J Eur Acad Dermatol and Venereol. 2008;22(3):356-62.

9. Hay RJ. Fungal infections. In: Cook GC, Zumla A. Manson's tropical diseases. London: Elsevier Health Sciences UK; 2008. p. 1169-70

10. Ahmed I, Ahmed Z, Nasreen S. Prevalence of tinea capitis and asymptomatic carriage amongst school going children. J Pak Assoc Derma. 2006;16(4):215-9. 